\title{
The impact of COVID-19 on the chiropractic profession: a cross-sectional survey on opinions, professional changes, and personal hardships of U.S. chiropractors
}

Shawn M Neff ( $\nabla$ shawn.neff@va.gov)

Martinsburg VA Medical Center https://orcid.org/0000-0002-8979-8260

Rebecca L. Deyo

Annabelle L. Mac Auley

Dana J. Lawrence

Research

Keywords: Chiropractic; COVID-19; Stress; Practice Characteristics; Immune System

Posted Date: September 4th, 2020

DOI: https://doi.org/10.21203/rs.3.rs-37901/v3

License: (c) (i) This work is licensed under a Creative Commons Attribution 4.0 International License.

Read Full License 
The authors have withdrawn this preprint from Research Square 